\title{
LA EMIGRACIÓN POLÍTICA Y LA OPOSICIÓN VIOLENTA A LA MONARQUÍA RESTAURADA (1897-1931)
}

por

\author{
EdUARDo GonZÁlez CALleJA \\ Instituto de Historia (CSIC)
}

RESUMEN: El presente trabajo pretende sacar a la luz las estrategias de enfrentamiento violento desplegadas por las diversas facciones de la oposición antimonárquica en el exilio durante el primer tercio del siglo XX. En paralelo, se estudian las respuestas gubernamentales a estas amenazas desestabilizadoras, que oscilaron entre la labor preventiva reflejada a fines del XIX en los primeros ensayos de coordinación internacional frente al terrorismo anarquista, y el endurecimiento de la defensa exterior del Estado que alcanzó su momento culminante durante la Dictadura de Primo de Rivera. Tanto la persistente labor subversiva de los grupos disidentes como la intransigencia del poder politico contribuyeron al deterioro irreversible de la imagen exterior del régimen monárquico a partir de los años veinte.

Palabras Clave: España. Historia Contemporánea. Restauración. Historia política. Oposición política. Emigración política.

ABSTRACT: This work examines the strategies of violent contention adopted by the various factions of the exiled Spanish anti-monarchical opposition during the first third of the twentieth century. In parallel, governmental responses to these threats are also analysed, with attention to their evolution from the first attempts at building international coalitions against anarchist terrorism in late nineteenth century, to the bardening of foreign defence policies during the Primo de Rivera dictatorship. Both

Archivos reseñados en las notas: $\mathrm{AGA}=$ Archivo General de la Administración (Alcalá de Henares); $A H N=$ Archivo Histórico Nacional (Madrid); AMAE = Archivo del Ministerio de Asuntos Exteriores (Madrid); AN=Archives Nationaux (París); ANC= Arxiu Nacional de Catalunya (Sant Cugat del Vallés); APPP =Archives de la Préfecture de Police de Paris; AQO=Archivo del Quai d'Orsay (París); ASMAE=Archivio Storico del Ministero degli Affari Esteri (Roma); PRO.FO=Public Record Office, Sección Foreign Office (Kew, Londres); SHM=Servicio Histórico Militar (Madrid). 
the subversive activities of dissident groups and the intransigence of repressive political power contributed to the irreversible damage to the international image of the monarchy from the 1920s onwards.

KEY WORDS: Spain. Contemporary History. Restoration. Political opposition. Political emigration.

De la terra incognita que alberga a la mayor parte de los exilios españoles contemporáneos, la Restauración es, quizás, el terreno más inexplorado, tanto por la debilidad numérica de los grupos afectados como por la presunta irrelevancia de sus actuaciones sobre la estabilidad política de régimen. En un artículo reciente hemos intentado destacar la importancia humana y política de la emigración carlista y republicana en el último cuarto del siglo XIX ${ }^{1}$, y señalado la variedad de implicaciones internas y externas de este fenómeno, que nosotros vinculábamos con el «hecho de frontera», es decir, con la creciente racionalización y definición de estas áreas limítrofes que forman uno de los más característicos atributos de soberanía del moderno Estado-nación ${ }^{2}$. En secuencia con esas primeras grandes oleadas de exiliados antialfonsinos, producidas entre 1876 y 1886 , el presente trabajo abordará dos etapas ciertamente no tan llamativas, pero no menos definitorias de la peculiar naturaleza de la emigración política durante la Restauración: la que va de la crisis finisecular al comienzo de la Guerra Europea, y el período acotado por la Dictadura de Primo de Rivera y la caída de la Monarquía. Ambos ciclos presentan características muy diferentes, tanto en la dinámica interna de los grupos exiliados como en las estrategias de control y/o represión implementadas por las autoridades de uno y otro lado de las fronteras, lo que a su vez conllevó importantes repercusiones de orden transnacional.

Del elenco de tareas que puede desplegar un grupo exiliado, nuestro análisis privilegiará la estrategia de oposición política, y dentro de ésta, la acción subversiva marcada por diversos grados de violencia. Este tipo de intervención pública puede resultar muy reveladora, ya que individualiza al exilio político frente a otros tipos de flujo migratorio, y pone de relieve rasgos muy particulares, tanto en la organización y fines del colectivo expatriado como en las actividades de control unilateral, bilateral o multilateral, de los gobiernos afectados por su actuación.

1 GonZÁlez CAlleja, Eduardo: «La frontera como protagonista histórico. Observaciones sobre la emigración y la resistencia políticas en la primera etapa de la Restauración», en Éxils et Migrations Hispaniques au XX Siècle/Exilios y Migraciones Ibéricas en el siglo XX (París), CERIC (Université Paris-VII), nº 3/4, 1997, pp. 14-36.

2 Sobre esta cuestión, vid. GIDDENS, Anthony: The nation-state and violence, Cambridge, Cambridge Polity Press, 1985 , pp. 88-90 y 120-121.

Hispania, LXII/2, núm. 211 (2002) 483-504 


\section{LAS ESTRATEGIAS SUBVERSIVAS DEL EXILIO ANARCO-REPUBLICANO (1896- 1911)}

El anarquismo en su versión terrorista fue una de las amenazas violentas que se cernieron sobre las sociedades occidentales en ese período histórico que, con escaso fundamento, se llamó Belle Époque. España no fue una excepción: tras la oleada de atentados de 1893-97, la expulsión forzosa del país de un importante contingente de dos centenares de anarquistas tras los «Procesos de Montjuïc» fue el acontecimiento fundacional de un nuevo exilio político, cuyas secuelas se mantendrían hasta los inicios de la segunda década del siglo ${ }^{3}$. La expulsión sumaria de este nutrido grupo de anarquistas por parte de las autoridades motivó graves roces diplomáticos con los gobiernos francés e inglés en el verano de $1897^{4}$. Cuando, a fuerza de poner a prueba la paciencia de las autoridades de Londres y París con nuevos envíos forzosos, estas puertas se cerraron, se especuló incluso con mandar a los presos libertarios a Hispanoamérica, Canadá o alguna lejana colonia españolas.

3 Una R.O. de 24-V-1897 señaló que 196 de los detenidos por el atentado de Cambios Nuevos debían ser extrañados fuera el reino o quedar en expectativa de destino (AMAE, Sección Histórica, Política Interior, Orden Público, Parte General, 1892-1898, leg. H 2750 y AGA, Asuntos Exteriores, Embajada en París, caja $\mathrm{n}^{\circ}$ 5831). Otras ocho personas fueron expulsadas del territorio nacional.

4 El 12-VI-1897, 52 anarquistas, entre ellos José Casanovas, Pere Coromines, Anselmo Lorenzo y Francesc Gana, fueron abandonados sin mayores trámites en Cerbère. Esta irregular actuación motivó una protesta oficial del embajador francés, quien advirtió que su gobierno no aceptaría más envíos en condiciones parecidas. Después de complicadas negociaciones diplomáticas, parte de los detenidos en Montjuïc, pero también otros sospechosos o simples anarquistas extranjeros, fueron expulsados a Francia, donde quedaron sometidos a vigilancia particular por la Sûreté. Las protestas oficiales francesas y el principio de acuerdo, en la documentación depositada en AMAE, Sección Histórica, Política Interior, Orden Público, Parte General, 1892-1898, leg. H 2750; AQO, Nouvelle Série, 1896-1918, Espagne, vol. 10, pp. $47-48$ y 53; AGA, Asuntos Exteriores, Embajada en París, caja n ${ }^{\circ} 583.1$ y SHM, Archivo General Militar, $2^{a}$ Sección, $4^{a}$ División, leg. 157, Orden Público en General, 1774-1892. El 17-VII se emitió una nueva R.O. por la que se prohibían más expediciones de este tipo, de modo que las autoridades francesas no permitieron el desembarco de 37 ácratas en el puerto de Marsella hasta no recibir la pertinente autorización del Ministerio de Estado. Vid. telegrama cifrado del embajador en París al subsecretario de Estado (22-VII-1897), en AGA, Asuntos Exteriores, Embajada en París, caja $n^{\circ}$ 5831. La negativa de los gobiernos galo y norteamericano a acoger a nuevos expulsados obligó al gabinete canovista a buscar destinos alternativos, como Gran Bretaña, pero el traslado sin previo aviso a Liverpool de un nuevo contingente de expatriados en VII-1897 obligó al gobierno británico a declarar que no estaba dispuesto a acoger un solo anarquista más en esas condiciones. El malestar del Consulado y de la Embajada británicos por este incidente, en carta de Wyndham al encargado de negocios George H. Barclay (Barcelona, 27VII-1897) y despacho de Drummond Wolff a Salisbury (San Sebastián, 30-VII-1897), en PRO.FO, $72 / 2035$. Las negociaciones diplomáticas con el gobierno inglés, en informes del embajador en Londres, conde de Casa Valencia, y del Consulado en Liverpool (23 y 29-VII-1897), en AMAE, Orden Público, Parte General, 1892-1898, leg. H 2750.

5 Las otras alternativas para la reubicación de los anarquistas, en informe de la agencia Reuter, comunicado por el embajador en Londres el 1-IX-1897 (AMAE, Orden Público, Parte General, 1892-1898, leg. H 2750). 
A inicios de 1900, los implicados en los procesos por terrorismo vieron conmutadas sus penas de cárcel por la de extrañamiento perpetuo o temporal. La mayor parte se instaló en Argel, Orán, París y Marsella, pero otros escogieron como destino Gran Bretaña. Lo cierto es que, incluso antes de las ejecuciones de Montjuï, los primeros exiliados españoles ya aparecían integrados, con correligionarios franceses e ingleses y con proscritos rusos e italianos, en agrupaciones ácratas y de librepensamiento que orquestaban la protesta internacional contra los abusos de la «España Inquisitorial» y no eran ajenas a la sugestión terrorista. Algunos informes reseñaban que el publicista francés Charles Malato desde el Comité Franco-Espagnol afincado en París y el italiano Enrico Malatesta desde Londres estaban proyectando una acción de venganza por la ejecución de sus camaradas de Barcelona, como en efecto ejecutó el anarquista Michele Angiolillo sobre Cánovas en agosto de $1897^{6}$.

A inicios de la nueva centuria, París era el principal punto de reunión de ácratas y republicanos de toda laya, apoyados por las ligas y organizaciones autóctonas de cariz internacionalista, masónico, antimilitarista, racionalista o de libre pensamiento ${ }^{7}$. En esta «hermandad revolucionaria» descollaban figuras como Pedro Vallina y Francisco Ferrer. A ellos habría de unirse Alejandro Lerroux, la joven figura del republicanismo barcelonés, que pronto se revelaría

6 Informe de la Police Générale del Ministère de l'Intérieur al Quai d'Orsay (París, 10-II-1897), en AQO, Nouvelle Série, 1896-1918, Espagne, vol. 10, pp. 31, 39-40 y 43. La reseña de una reunión en Londres de los anarquistas Tarrida, Louise Michel y otros para la recaudación de fondos con vistas al traslado de agentes anarquistas a España, en informe del embajador francés en Londres (1V-1897), en AQO, Nouvelle Série, 1896-1918, Espagne, vol. 1, p. 141. Como es bien sabido, Angiolillo se había relacionado con los dirigentes del Spanish Atrocities Commitee y con alguno de los anarquistas desterrados tras los procesos de Montjuï, como Juan B. Oller, Francesc Gana y Fernando Tarrida, éste último presunto agente del «Comité Cuba Libre» en Londres. Luego pasó a París a inicios de junio de 1897, donde conferenció con un grupo de anarquistas y republicanos extremistas españoles y franceses: Anselmo Lorenzo, Francisco Ferrer y Henry de Rochefort. También con el puertorriqueño dr. Betances (representante de los independentisas cubanos) y con Malato, quien le dio 400 francos para el viaje a España.

7 Según Vallina, Pedro: Mis Memorias, Caracas, Ed. Tierra y Libertad, vol. I, pp. 94 y 103, los anarquistas españoles activos en París "no pasarían de 50", y se reunían una vez por semana en el Faubourg St. Antoine para activar la lucha contra el régimen español, mientras que «los republicanos españoles expatriados en aquella época en París, como los que durante la dictadura de Primo de Rivera se exiliaron en Francia, no hicieron otra cosa que frecuentar cafés, formar tertulias sin preocuparse lo más mínimo para organizar la acción contra la monarquía alfonsina. Esto mismo hacen ahora socialistas y republicanos, porque esperan que Franco se muera para regresar a España" (p. 100 nota 1). Según PREMISLER, Sylvie: «L'émigration politique espagnole en France (1872-1876, 1894-1912», Revue Caravelle, $\mathrm{n}^{\circ} 21,1973$, pp. 131-133, los españoles fueron, con los rusos e italianos, uno de los colectivos anarquistas más activos y vigilados por la Policía gala. A inicios de 1905 , los anarquistas del grupo al que pertenecía Vallina se relacionaban muy estrechamente con los ácratas italianos exiliados en París, donde ese mismo año se creó una federación de 21 grupos libertarios. Las redacciones de publicaciones como Hispania o L'Espagne Inquisitoriale eran los lugares de reunión de los exiliados, sobre todo los activistas ácratas.

Hispania, LXII/2, núm. 211 (2002) 483-504 
como el interlocutor imprescindible para obtener apoyo económico de los republicanos exiliados en varios países de América. La proximidad cotidiana entre los grupos anarquistas y republicanos, los rasgos rupturistas de sus respectivas culturas políticas y el aliento que recibían de diversas asociaciones europeas de tono revolucionario fueron elementos que, poco a poco, hicieron derivar la mutua simpatía hacia una concordancia de planteamientos subversivos. El 10 de diciembre de 1904, los republicanos exiliados en París crearon una Junta de acción y unión republicana, que colaboró hasta julio de 1906 con el «grupo de acción revolucionaria» anarquista del que formaba parte Malato, cuyas estrechas relaciones con Tarrida del Mármol, Malatesta, Kropotkin, Réclus, Sebastien Faure o Ferrer le transformaban en uno de los grandes animadores del movimiento libertario en la capital francesa, pero también en el interior de España ${ }^{8}$. A este foco conspirador se vincularon también, en sus frecuentes viajes al extranjero, Ferrer y Lerroux, que llegaron a transformarse en los virtuales brazos económico y político de una conjura que se basaba en una acción típicamente terrorista (un regicidio) que actuaría como desencadenante de un levantamiento popular revolucionario en alguna gran ciudad española, concretamente Barcelona9.

Como señala acertadamente Álvarez Junco, «fue precisamente entre Vallina, Estévanez y el grupo republicano y anarquista de París donde se fraguó, entre 1903 y 1904, la nueva oleada de "acción" ${ }^{10}$. Durante la comprometida primera visita oficial del rey Alfonso a Barcelona en abril de 1904, Maura estimuló el celo de los numerosos confidentes a sueldo de las embajadas españolas, y solicitó a éstas y a los gobiernos extranjeros (algunos de los cuales, como Italia, Francia o Alemania, disponían de servicios policiales de información antianarquista en sus consulados de la ciudad condal) una intensificación de la vigilancia sobre los libertarios más significados residentes en el Midi y en los puertos europeos conectados directamente con Barcelona, Baleares, plazas de África, Málaga, Cádiz y Sevilla ${ }^{11}$. El viaje de don Alfonso a París en mayo de 1905 fue «preparado» por los medios ácratas cercanos al «Comité de acción revolucionaria». La desarticulación parcial por la Sûreté del complot que des-

8 Sobre este "grupo de acción revolucionaria», vid. ÁLvAREZ JunCO, José: El emperador del Paralelo. Lerroux y la demagogia populista, Madrid, Alianza Editorial, 1990, pp. 293-300.

9 En un rapport del comisario especial Bonnecarrère, escrito en la estación de Cerbère el 18VII-1904, se asegura que Ferrer, con sus frecuentes idas y venidas a la capital francesa, actuaba de enlace entre el Comité Internacional Anarquista de Barcelona [sic] y el Centro Anarquista de París (APPP, Série BA ${ }^{A}$, Francisco Ferrer y Guardia, caja 1075).

10 Álvarez JunCO, El emperador..., pp. 292-294.

1 ASMAE, Polizia Internazionale, Anarchici in Svizzera, Spagna, Stati Uniti, 1898-1906, caja 35. Una Circular del Ministerio de Estado (21-IX-1904) a los cónsules en el Sur de Francia para acentuar la vigilancia de las actividades de los anarquistas españoles en los aledaños de la frontera catalana, y un informe del cónsul en Marsella (22-IX-1904) sobre confabulaciones anarquistas tras la llegada de Ferrer a la ciudad, en AMAE, Sección Histórica, Política Interior, Orden Público, Parte General, 1899-1908, leg. H 2751. 
embocó en el atentado contra el monarca español y el presidente Loubet en la rue de Rohan llevó a la detención y procesamiento de varios anarquistas exiliados, entre los cuales figuraba el propio Vallina, pero otros presuntos implicados, como el joven Mateo Morral, pudieron eludir el acoso policial. Lo que a estas alturas no cabe duda es que los complots contra Alfonso XIII de 1905 y 1906 fueron alentados por el grupo conspirador repartido en Barcelona, París y Londres, y que contaba con la participación activa de personalidades como Ferrer, Estévanez y Lerroux. Tampoco es menos cierto que los atentados sucesivos contra la vida del rey hicieron más difíciles las actividades subversivas del exilio anarco-republicano, tanto en sus movimientos en los países de acogida como en sus comunicaciones con el interior de España.

Mientras que Ferrer, implicado en el atentado de la calle Mayor, obtenía su libertad a mediados de 1907 tras una intensa campaña internacional en su favor, Lerroux hubo de refugiarse en Perpignan y luego en París para librarse de una condena por delito de imprenta. La Embajada española expresó su deseo de que tanto Ferrer como Lerroux fueran trasladados al Norte del Loira; extrañamiento que, en efecto, sufrió el tribuno radical ${ }^{12}$. La vigilancia se hizo tan estrecha que, en octubre de 1907, Lerroux decidió viajar a Sudamérica con el objetivo de recabar ayuda crematística de ciertos grupos cubanos y de la Liga Republicana Española de Buenos Aires. Mientras tanto, Ferrer no perdía el tiempo, y preparaba desde Barcelona, Londres y París el terreno para acentuar el sentimiento de rebeldía que desembocase en el tan deseado movimiento revolucionario $^{13}$. La «Semana Trágica» de julio de 1909 produjo una nueva oleada de extrañamientos, destierros de extranjeros y varios centenares de exiliados voluntarios a Francia. Por contra, la emigración política tuvo un papel casi testimonial en la impresionante campaña internacional de protesta por el procesamiento y ejecución de Ferrer, que fue animada por anarquistas, socialistas y masones, pero también por liberales, librepensadores e intelectuales de muy diversas tendencias.

12 Informe del Deuxième Bureau de la Sûreté Générale al prefecto de Policía de París (6-III-1908), en APPP, Série B ${ }^{A}$, caja 1075. Francisco Ferrer y Guardia. Cuando en abril se rumoreó la creación de un partido republicano revolucionario dirigido por un triunvirato (Lerroux, Estévanez y Sol y Ortega), el embajador León y Castillo suplicó al gobierno francés que impidiera en lo posible a los anarquistas y agitadores españoles residir en el sur del país. Vid. despacho del Ministre des Affaires Etrangères al Président du Conseil et Ministre de I'Intérieur (Sûreté Générale, París, 20-IV-1908. Respuestas de los diferentes prefectos por departamentos entre III/V-1908 y acta de la reunión de León y Castillo con Clemenceau (7-VI-1908) para deliberar sobre la cuestión, en AN, Série F ${ }^{7}$, leg. 13066: Surveillance des anarchistes et révolutionnaires espagnols, 1908-1909.

13 Los informes de confidentes como Sannois en 1908-09 evidencian la impresionante red de vigilancia establecida por los embajadores en París, y demuestran la estrecha vinculación entre los diversos personajes de esta trama complotista, los continuos viajes de Ferrer y la constante comunicación con Lerroux en América. El seguimiento de Lerroux en Buenos Aires, y de Vallina y Ferrer en Londres a inicios de V-1909, en AMAE, Sección Histórica, Política Interior, Orden Público, Parte General, 1899-1908, leg. H 2751. 
Los preparativos para una irrupción fronteriza en agosto-octubre son una faceta muy poco conocida de los disturbios barceloneses de 1909: el 7 de agosto, la Embajada española en París y la Policía francesa intercambiaron mensajes sobre la posibilidad de que los españoles exiliados en Francia se concentraran en el Midi para intentar un golpe revolucionario con el apoyo de Ferrer «qui doit se tenir non loin de la frontière» ${ }^{14}$. El triunfo revolucionario del republicanismo portugués, durante tanto tiempo vinculado a los proyectos insurreccionales de sus homónimos españoles, estimuló la agitación a uno y otro lado de la frontera durante el verano y el otoño de 1910. La «mano de obra» que difundiría el "contagio» subversivo la proporcionarían los miles de jóvenes -especialmente catalanes- evadidos del territorio nacional para no participar en la guerra de África, y los cientos de revolucionarios españoles fugitivos con motivo de la represión de la «Semana Sangrienta» del año anterior, que, faltos de dinero, se habían extendido por las poblaciones próximas a la frontera franco-española, como Perpignan, Cerbère, Port-Vendres o Port-Bou ${ }^{15}$. Según el dirigente socialista catalán Fabra Ribas, unos 3.000 emigrados, buena aparte de ellos autoexiliados tras la «Semana Trágica», partirían desde Perpignan, Toulouse, Pau y Bayona hacia la Cerdaña, el Valle de Arán y Aragón, armados con revólveres para provocar una insurrección que coincidiría con la huelga general que se iba a declarar en Barcelona, Valencia y Zaragoza ${ }^{16}$. Los fracasos del motín republicano producido en la fragata Numancia en agosto de 1911 y de la huelga con visos insurreccionales del mes siguiente, conllevaron la clausura definitiva de las actividades revolucionarias del exilio anarco-republicano. Sea como fuere, la pérdida de mordiente revolucionario del lerrouxismo en la década de los diez,

14 La agitación fronteriza, en rapport del $3^{\mathrm{e}}$ Bureau («Gilles», 7-VIII-1909), en APPP, Série B ${ }^{\mathrm{A}}$, Francisco Ferrer y Guardia, caja 1075. Una confidencia de Sannois (7-VIII-1909) hacía notar que Ferrer iba a sufragar el viaje de los militantes anarquistas de París a la frontera (AGA, Asuntos Exteriores, Embajada en París, caja $n^{\circ}$ 5892). Un despacho del cónsul en Perpignan (11-VIII-1909) denunciaba que la frontera española de Puigcerdà a Port Bou no estaba vigilada, y advertía que los refugiados en la zona tras la «Semana Trágica» «esperan que vuelvan a moverse los revolucionarios para ayudarles y apoderarse de cuantas armas encuentren en los pueblos. Procuraré ver si hay medio de que sean internados» (AMAE, Sección Histórica, Política Interior, Orden Público, Parte General, 1892-1898, leg. H 2750).

15 Según LEROY, Constant (seud. de Miguel Villalobos MORENO): Los secretos del anarquismo (sensacionales revelaciones de un decepcionado). Asesinato de Canalejas y el caso Ferrer, México, Librería Renacimiento, 1913, pp. 28-30, un Comité Pro Revolución Española animado por Ferrer y luego por Malato, que funcionó entre 1909 y 1911, procedió a la captación de voluntarios a través de las Bolsas de Trabajo francesas, pero Canalejas, al corriente de estos manejos, truncó los preparativos concediendo una amplia amnistía a la que se acogió la mayoría de los fugitivos. Sobre la emigración forzosa a París de un centenar de obreros de Barcelona y alrededores tras la «Semana Trágica», vid. SALUT, Emili: Vivers de revolucionaris. Apunts històrics del districte cinquè, Barcelona, Llibrería Catalònia, 1938, pp. 180-182.

16 La información de Fabra Ribas, en M2348V (París, 25-IX-1911), en AN, Série $\mathrm{F}^{7}$, Surveillance des anarchistes et révolutionnaires espagnols résidents en France, 1910-1912, leg. 13067. 
que coincidía con el declive definitivo del anarquismo nihilista (sustituido por el socialismo y el sindicalismo revolucionario en el favor de las masas obreras de las zonas industriales) y con la consolidación del liberalismo como opción gubernamental dominante (que, fiel a su proyecto de apertura hacia otros sectores de izquierda, puso los medios legales para la recuperación política del exilio), cerró este primer ciclo subversivo transfronterizo de la España del siglo XX.

\section{LA «PSICOSIS» ANTIANARQUISTA Y LOS PRIMEROS ENSAYOS DE COORDINA- CIÓN INTERNACIONAL}

En el tránsito del siglo XIX al XX, la lucha contra las amenazas de desestabilización política procedentes del exilio vino caracterizada por la voluntad de coordinación a escala internacional. Ello fue debido a dos circunstancias básicas: en primer lugar, la entidad pretendidamente global de la amenaza terrorista, supuestamente dirigida por una oscura y temible «Internacional Negra» de obediencia libertaria; en segundo, la existencia mayoritaria en Europa de regímenes liberal-parlamentarios, cuya consonancia política y jurídica eliminaba obstáculos para la concertación de acuerdos de cooperación bilateral o multilateral entre los distintos gobiernos. Unos convenios que, entre otras cuestiones de interés, estipulaban una más estrecha vigilancia de la emigración política, sea cual fuere su ideología y sus actividades.

Desde la última década del siglo, los gabinetes españoles fueron grandes impulsores de este tipo de acuerdos. En 1891, el ministro de la Gobernación Francisco Silvela expuso un proyecto de entente internacional contra el anarquismo, en la línea de los ensayos efectuados años atrás por los gobiernos alemán y ruso, pero todos los países consultados, con la excepción de AustriaHungría, respondieron de forma negativa ${ }^{17}$. Después de la oleada de atentados que sufrió Barcelona a fines de 1893, Moret también presentó al Quai d'Orsay y al Foreign Office un proyecto de acuerdo internacional relativo a las precauciones a tomar para desarticular las tentativas anarquistas ${ }^{18}$, y tras el asesinato de Cánovas el Ministerio de Estado relanzó la vieja propuesta para la adopción de medidas internacionales contra el terrorismo. No fue sino un año después cuando la proliferación de magnicidios a escala continental desembocó en la convocatoria, para noviembre y diciembre de 1898 , de una Conferencia Internacional para la defensa social contra los anarquistas a celebrar en Italia, donde los Estados implicados tratarían de coordinar su labor antiterrorista ${ }^{19}$. La reunión

\footnotetext{
17 La propuesta de Silvela, en APPP, Série BA , Anarchistes en Espagne, caja 1511.

18 «Proyecto de acción común internacional para la represión del anarquismo. Estado de la cuestión a 8-I-1894», en AMAE, Sección Histórica, Política Interior, Orden Público, Parte General, 1892-1898, leg. H 2750.

19 Vid. Circular del ministro de Asuntos Exteriores italiano, vicealmirante Napoleone Canevaro, a las Embajadas italianas en Europa (20-IX-1898), suplicando informasen a los diversos gobier- 
de Roma, cuyo protocolo final fue firmado en julio de 1899, sirvió al menos para sentar las bases de ulteriores acuerdos antianarquistas de alcance bilateral y multilateral, pero comenzó a caer en desuso a inicios de siglo, de modo que los gobiernos imperiales austríaco, ruso y alemán decidieron lanzar una nueva iniciativa: un protocolo de recíproca información, firmado en San Petersburgo el 14 de marzo de 1904, por el que todo activista ácrata expulsado de un Estado contratante debía ser conducido por la ruta más corta a su nación de origen, sin utilizar la vía diplomática. Cada gobierno establecería una oficina central de Policía destinada a recoger las informaciones sobre los anarquistas y sus actuaciones $^{20}$. Sin embargo, estos primeros acuerdos de coordinación policial tuvieron una eficacia muy discreta en el tratamiento de un problema como el terrorismo ácrata, de modo que los gobiernos se vieron obligados a tomar sus propias medidas de control y vigilancia, o solicitar ayuda de sus homólogos extranjeros en circunstancias puntuales de carácter excepcional. Así sucedió con motivo del matrimonio real celebrado en Madrid el 31 de mayo de 1906: el Ministerio de Estado movilizó a todo el aparato consular y recabó la colaboración policial de los gobiernos francés, italiano y británico ${ }^{21}$. Tras el atentado de Morral, y de acuerdo con el gobierno italiano, el Ministerio de Estado trató una vez más de relanzar la convocatoria de un acuerdo internacional contra el anarquismo, que contó con el apoyo de Suecia, pero con la indiferencia del resto de los gobiernos del continente ${ }^{22}$.

nos sobre la convocatoria de la Conferencia. Carta de invitación del encargado de negocios italiano, di Cariati, al ministro de Estado español (29-X-1898) y minuta de aceptación de Almodóvar del Río (2-XI-1898), en AMAE, Sección Histórica, Política Interior, Orden Público, Parte General, 18921898 , leg. H 2750.

20 El proyecto inicial de Protocolo (12-IV-1902) y la adhesión de España al Protocolo antianarquista de San Petersburgo de 14-III-1904, remitido por el Ministerio de Estado al de la Gobernación el 15-VI-1904, en AMAE, Sección Histórica, Política Interior, Orden Público, Parte General, 1911-1919, leg. H 2753.

21 Carta del ministro de la Gobernación al embajador en París (22-III-1906) y telegrama de León y Castillo a Romanones y Moret (20-III-1906), en AGA, Asuntos Exteriores, Embajada en París, caja $n^{\circ} 5882$. Una carta de Romanones al duque de Almodóvar del Río (12-V-1906) solicitaba que los gobiernos de Francia, Italia y Gran Bretaña diesen conocimiento de la salida para España de anarquistas sopechosos, y sus policías controlasen los movimientos de los ácratas más conocidos. El inspector especial de la Sûreté, Jules Bonnecarrère, se puso a disposición del gobierno civil de Barcelona para intercambiar información sobre las actividades violentas de ciertos grupos anarcorepublicanos. Tras el atentado, se pidió a numerosos países, desde Uruguay a Gran Bretaña, que extremasen la vigilancia sobre los anarquistas españoles exiliados (AMAE, Sección Histórica, Política Interior, Orden Público, Parte General, 1899-1908, leg. H 2751).

22 R.O. del Ministerio de Estado (4-VII-1906) sobre convocatoria de una conferencia internacional antianarquista. Tras el atentado contra los reyes de España, el gobierno de Italia había propuesto precisamente una nueva conferencia antianarquista, para lo cual inició un intercambio de notas con otros gobiernos («Pour combattre l'anarchie», L'Action, 5 y 6-VI-1906, p. 1). El ministro del Interior transalpino, Tommaso Tittoni, trató entonces de coordinar su propuesta con la sugerencia española (despachos de la Embajada en Roma, 19-VI y 17-VIII-1906), pero no parece que 
De nuevo tras la «Semana Trágica», los gobiernos liberales pusieron gran empeño en incrementar la cooperación internacional en materia policial, aunque la eficacia de las labores de represión y vigilancia en el exterior resultaba muy relativa. Los primeros organismos internacionales de Policía surgirían como respuesta a problemas puntuales que cada país se veía incapaz de gestionar: en 1912, la Conferencia de Berlín puso los cimientos para celebrar en 1914 en Mónaco el I Congreso de Policía Judicial, donde se creó una Comisión Internacional que dió lugar, tras la Segunda Guerra Mundial, a Interpol.

\section{LA FRONTERA RECUPERA EL PROTAGONISMO: LAS EMIGRACIONES ANAR- QUISTA Y CATALANISTA Y LA RESISTENCIA ARMADA CONTRA LA DICTADURA}

El estallido de la Gran Guerra transformó radicalmente el panorama de la emigración política española. Las medidas de férreo control político de la retaguardia implementadas por los Ejecutivos de los países beligerantes dificultaron las actividades de un exilio languideciente, sumergido además por la oleada de mano de obra extranjera que los gobiernos, especialmente el francés, aceptaron con el objeto de intensificar la producción en esos momentos de emergencia nacional. Paradójicamente, España se transformó en centro de acogida de refugiados de toda clase y condición, algunos de los cuales actuaron como agentes encubiertos de las potencias combatientes, alentando una serie de acciones ilegales que hicieron derivar la conflictividad sociolaboral hacia la confrontación violenta. En el caso concreto de Barcelona, la deriva pistoleril que experimentó la lucha social a partir de 1916-18 aparece directamente vinculada con el advenimiento de la Dictadura de Primo de Rivera.

Resulta casi inevitable que el establecimiento de un sistema autoritario suponga un cambio radical en la dinámica interna y externa de la emigración política. En España, el particular ensañamiento con que la Dictadura trató a los grupos disidentes más extremos provocó nuevas oleadas de refugiados. Sin embargo, el exilio antiprimorriverista presentó una serie de características bastante novedosas. En primer lugar, la emigración política se dirigió casi en exclusiva a Francia, especialmente al Midi, Argelia y las grandes urbes como $\mathrm{Pa}$ rís o Lyon. La presencia de regímenes dictatoriales en el resto de los países vecinos (Italia desde 1925 y Portugal un año más tarde) no dejaba lugar a mejores alternativas, aunque un sector minoritario de expatriados también optó por Bélgica, la Unión Soviética o América Latina. Otras razones para atravesar los Pirineos era la presencia, entre 1924 y 1926, del gobierno del Cartel des

estas iniciativas fueran acogidas con especial entusiasmo en el resto de Europa (AMAE, Sección Histórica, Política Interior, Orden Público, Parte General, 1899-1908, leg. H 2751). El Foreign Office aceptó la colaboración policial directa con España para la vigilancia del anarquismo (despacho de Londres 15-VIII-1906, en AMAE, Sección Histórica, Política Interior, Orden Público, Parte General, 1899-1908, leg. H 2751).

Hispania, LXII/2, núm. 211 (2002) 483-504 
Gauches, que favoreció las actividades de los grupos de izquierda, y la presencia de una importante colonia peninsular, que se había incrementado notablemente por la demanda de mano de obra de la posguerra. En segundo término, la oposición antidictatorial se vio obligada a constituir organismos estables de actuación política en el extranjero (comités de relaciones, oficinas de propagan$\mathrm{da}$, comités o juntas revolucionarias, etc.) que pudiesen paliar la intensa represión ejercitada sobre su correligionarios del interior de España; aunque, como resulta un rasgo común de muchos exilios, resultaron inevitables los conflictos de competencias y de propósito entre las instancias del interior y del exterior. En tercer lugar, la estrategia política estuvo marcada por la voluntad de aglutinar al mayor número posible de fuerzas de la emigración en un frente común antidictatorial, cuyo modo de lucha más característico fue la irrupción fronteriza. Por último, la resistencia armada transformó al exilio antidictatorial en un problema internacional de primer orden, que en ocasiones puso al desnudo las maniobras de las potencias regionales en torno al frágil equilibrio en el Mediterráneo.

No cabe duda que el exilio más importante en número y en actividad fue el anarquista. La represión de la época de Martínez Anido en Barcelona y las primeras medidas punitivas de Primo desmantelaron virtualmente a la CNT, e impulsaron a muchos de sus miembros a probar fortuna en América y Europa, especialmente en Francia. Según el testimonio de un fundador de la FAI, en la época de la Dictadura existía en el país vecino un mayor número de grupos anarquistas del que existía en España ${ }^{23}$. Muy pronto, los ácratas exiliados en Francia quedaron encuadrados en una Liga de Militantes, y fomentaron la organización de nuevos "grupos de acción». En una fecha no especificada de febrero de 1924 se constituyó en París un Comité de Relaciones Anarquistas (CRA) encargado de dar forma a una futura Federación de Grupos Anarquistas de Lengua Española residentes en Francia. Este Comité decidió establecer contactos con otros grupos libertarios residentes en Francia, y con otras formaciones (como los catalanistas de Macià, republicanos, nacionalistas vascos, militares y exiliados liberales) para unificar fuerzas y ejecutar un movimiento insurreccional conjunto contra la Dictadura.

En noviembre de 1924, el CRA organizó casi sin ayuda una irrupción armada por la frontera española, que estimulase una rebelión en los puntos de España con mayor presencia cenetista, como Barcelona o Zaragoza. En la noche del 4 al 5, una primera expedición de cerca de un millar de anarquistas y catalanistas, procedentes de Lyon, París, Marsella, Burdeos, Nancy, Beziers, Toulouse, St. Étienne y otras localidades se dirigió en pequeños grupos a San Juan de Luz y Perpignan, pero al intentar pasar la muga por la localidad navarra de Vera de Bidasoa, fue repelida por la Policía española y hubo de retirarse hacia Hendaya, donde la Gendarmería arrestó a veinte españoles y a un fran-

${ }_{23}$ El movimiento libertario español, suplemento de Cuadernos de Ruedo Ibérico, Paris, Ruedo Ibérico, 1974 , p. 289. 
cés ${ }^{24}$. La expedición encargada de irrumpir por Cataluña no tuvo mejor suerte, ya que al llegar a Perpignan el grupo fue dispersado por la policía francesa, de modo que la proyectada «marcha sobre Barcelona» quedó frustrada completamente ${ }^{25}$. A pesar de los arrestos practicados en Perpignan y del fracaso de Vera, más de seiscientos sindicalistas y catalanistas concentrados en Beziers permanecieron en alerta durante días, al acecho de un nuevo movimiento ${ }^{26}$.

La intentona de Vera ofreció la excusa oportuna para que la Prefectura del Sena desencadenara una intensa campaña de persecución contra los anarquistas refugiados en la capital francesa. Un informe de la Policía española señalaba la situación de los grupos anarquistas españoles residentes en Francia en la primavera de 1925:

«Descartado París como centro de las organizaciones libertarias, sólo quedan Lyon y Burdeos, que cuentan cada una con dos grupos; siguiendo el orden de importancia Beziers, Toulouse, Narbonne, Montpellier, Lezignan, Perpignan y Tarbes que cuentan cada uno con un grupo y el Departamento del Gard que tiene otro. En todas las localidades citadas los grupos son permanentes. Hay también diseminados un poco por cada lado anarquistas individualistas principalmente en Limoges, Clermont-Ferrand, Bayonne, Pau, Libourne (Gironde), Avignon, Cette y otras»"27.

No cabe duda de que, en su conjunto, la emigración anarquista mantuvo durante la Dictadura un influjo determinante sobre buena parte de la organización cenetista, precipitando intentonas insurreccionales fallidas como la de noviembre de 1924, pero convocando también reuniones donde se debatió el

\footnotetext{
24 Un informe del cónsul en Bayona (10-XI-1924) señala que los implicados en Vera formaban «un grupo de unos cuarenta individuos, en su mayoría jóvenes de 20 a 25 años», todos excepto tres residentes en París. El 14-XI, este mismo funcionario enviaba una lista con datos de los detenidos en Bayona: uno tenía 20 años, dos tenían 21, otros dos tenían 22, tres tenían 23, uno 24, dos 27,2 de 28,2 de 29 , uno de 30 , dos de 32 y uno de 36 años. La mayor parte eran obreros procedentes de Castilla la Vieja, presuntamente prófugos del servicio militar. El comisario especial en Hendaya señalaba el 31-XII-1924 que del medio centenar de detenidos, diez eran separatistas que parecían haber sido pagados por el Casal Català de Perpignan (AQO, Série Z, Europe, 1918-1929, Espagne, leg. 45, p. 82).

25 Informe del cónsul en Perpignan (9-XI-1924) sobre hallazgo de armas y detención de 22 españoles cerca de la estación (AGA, Asuntos Exteriores, Embajada en París, caja $n^{\circ}$ 6330). Como en el caso de Vera, la mayor parte eran jornaleros con domicilio en París, y con edades que oscilaban entre los 20 y los 26 años.

26 En Toulouse, el cónsul español en Toulouse advertía el 20-XI-1924 que «el espíritu de revuelta no ha decaído por el contratiempo sufrido en Vera y que por el contrario, el reclutamiento de individuos dispuestos al sacrificio continúa con más entusiasmo que nunca» (AHN, Gobernación, Serie A, leg. 42A, exp. $n^{\circ} 11$ y AGA, Asuntos Exteriores, Embajada en París, caja $n^{\circ}$ 6330).

27 Despacho del cónsul en Toulouse al embajador en París (21-IV-1925), enviando un informe del agente de Vigilancia Juan Antonio Fernández de 20-IV (AGA, Asuntos Exteriores, Embajada en París, caja $n^{\circ}$ 6073).
} 
futuro del movimiento libertario. En el Congreso celebrado en Lyon en junio de 1925 se sentaron las bases de la Federación de Grupos Anarquistas de Lengua Española, que se constituiría en esa ciudad en 1926 y actuaría como nexo de unión entre grupos anarquistas de España y Portugal y los exiliados en Francia. Esta Federación convocó en mayo de 1926 un Congreso en Marsella donde se autodefinió como netamente anarquista, y rechazó colaborar con organizaciones ajenas a la $\mathrm{CNT}^{28}$. El experimento organizativo iniciado en Francia cristalizaría poco después en la FAI, heredera natural de estos primeros intentos de coordinación de los «grupos de afinidad».

El otro grupo de emigrados que desplegó una actividad de oposición constante contra la Dictadura fue el catalanismo radical. Exiliado a mediados de octubre de 1923 para eludir una orden de detención, Francesc Macià se instaló en un principio en Perpignan, donde estableció su secretariado con el apoyo del compositor Josep Fontbernat Verdaguer ${ }^{29}$. Sin embargo, tras unos incidentes en el transcurso de unos juegos florales celebrados en Toulouse, el dirigente de Estat Català fue obligado a fines de noviembre a fijar su residencia lejos de la frontera ${ }^{30}$. Macià pasó entonces a instalarse en Bois-Colombes, en la banlieue parisina. También organizó un Comité Separatista Català (que era en realidad una oficina de conspiración con visos de cuartel general en campaña) en el número 92 de la rue Richelieu de la capital francesa, donde la colonia separatista catalana estaba animada por jóvenes desertores del servicio militar en Marruecos, excombatientes de la conflagración europea cautivados por el frenesí parisino de los «années folles», emigrantes económicos de la guerra y la inmediata posguerra poco dispuestos a retornar a la turbulenta Cataluña del pistolerismo

28 Sobre las actividades políticas de los exiliados anarquistas en Marsella y la vigilancia estrecha de la Policía francesa, vid. los resúmenes de las Mémoires de Tercer Ciclo defendidas en la Faculté des Lettres de Aix-en-Provence, de Boulanger, Patrick: Les Espagnols à Marseille, 1880-1900; Claude ROUX, Les Espagnols à Marseille, de 1900 à 1925 y BENTOSELA, Fernand: Les évenements d'Espagne et Copinion Marseillaise de 1923 à 1931, en Bulletin du C.I.R.A., $\mathrm{n}^{\text {os }} 9$ (1972-1973) y 10 (1974).

29 Ya el 29-VIII-1919, el cónsul en Perpignan había informado de las actividades separatistas de Fontbernat en la ciudad (AMAE, Sección Histórica, Política Interior, Autonomía y Separatismo, leg. H 2824). El cónsul español en Toulouse informó el 5-V-1924 que «el foco creado aquí y mantenido por Fombernat [sic], es muy peligroso, porque este individuo ha tenido la habilidad de crearse colaboradores activos en el elemento francés, comienza a adoptar actitudes de rebeldía y procacidad que puede originar movimientos serios y de escándalo. A sueldo antes de Puig y Cadafalch y hoy mercenario de Macià, este sujeto de costumbres morales dudosas y de historia oscura es un resorte del que se valen Macià y sus amigos para intentarlo todo. Su Orfeón, es un centro de conspiración, y siguiendo el ejemplo de sus maestros catalanes, se sirve de la música popular y regional para educar las juventudes que le rodean en una atmósfera de odio y rencor para todo lo español que es preciso cortar de raíz si se quiere evitar males futuros» (AGA, Asuntos Exteriores, Embajada en París, caja $\mathrm{n}^{\circ}$ 6331).

30 Copia de un mensaje del prefecto de Pirineos Orientales al Presidente del Consejo y ministro de Asuntos Exteriores, Raymond Poincaré (Perpignan, 24-IX-1923), en AQO, Série Z, Europe, 1918-1929, Espagne, leg. 44, p. 258. 
y otros nacionalistas que habían impulsado en 1922-23 la creación de la sociedad Acció Radical Catalana. Se reunían habitualmente en un café del boulevard Saint-Germain, mientras que la oficina macianista de la rue Richelieu hacía las veces de foco revolucionario y de sala de redacción del Butlletí de l'Estat Català.

Durante estos años de actividad opositora, Estat Catalá actuó en tres diferentes teatros de operaciones: Francia, Cataluña (que actuaron alternativamente como frente y como retaguardia de sus proyectos insurreccionales) y América; esta útima como apoyo logístico, tanto en la orquestación de campañas de propaganda a nivel internacional como en la provisión de fondos para la lucha, a imagen de la labor realizada por las organizaciones de emigrados que apoyaban al nacionalismo irlandés desde los Estados Unidos ${ }^{31}$. Ya en noviembre de 1923 se sucedieron las reuniones entre sindicalistas, catalanistas de izquierda y algunos republicanos en Perpignan, en lo que puede calificarse como primer conato de conspiración contra la Dictadura ${ }^{32}$. Se llegó a un principio de acuerdo para impulsar una conspiración de republicanos y macianistas con apoyo anarcosindicalista y con conexiones blasquistas, nacionalistas vascas y comunistas, para la proclamación de la República federal en España ${ }^{33}$.

El triunfo del Cartel des Gauches en mayo de 1924 permitió que el anarcosindicalismo y Estat Català gozaran de mayor libertad de movimientos en el país vecino. Macià dio inicio a un período de frenética actividad conspirativa en París, Toulouse (apoyado por el Casal Català de la ciudad), Perpignan (donde el Catalunya Club trataba de captar a los refugiados) y otras localidades cercanas a la frontera. Los constantes y detallados informes de los diplomáticos españoles indican que en las inmediaciones de París (bosques de Saint-Cloud, Fontainebleau, Garches, Marne-la-Coquette, Marly-le-Roi, etc.), Josep Carner-Ribalta supervisaba las evoluciones de medio centenar de jóvenes «oficiales» en ejercicios a campo abierto. Los almogàvers (es decir, los milicianos de la organización

31 El Comité Separatista Català de la rue Richelieu estrechó relaciones con la mayor parte de las entidades catalanistas en el extranjero, donde desde 1921-22 habían comenzado a formarse Clubs Separatistes Catalans sobre el modelo de los Irish Freedom Friends de Norteamérica. Vid. «Bases per les que se regeix el Grop separatista Català de Paris» y «Manaments de la Federación Internacional de Clubs Separatistes Catalans», en ANC, Fons Francesc Macià, caja 23, exp. $n^{\circ}$ 03.08.05. Vid. también «Manaments de la Federació Internacional de Clubs S.C. aceptats i a fer acceptar pels seus components, pel Grop S.C. de Paris", en anexo al informe del Consulado en Toulouse de 30-IX1924. De la lista de 50 entidades catalanas establecidas en Chile, Uruguay, Paraguay, México, Estados Unidos, Cuba, Argentina y Francia, sólo 12 no estaban en relación directa con Estat Català (AGA, Asuntos Exteriores, Embajada en París, caja n ${ }^{\circ}$ 6331).

32 Marco Miranda, Vicente: Las conspiraciones contra la Dictadura (1923-1930), Madrid, Impta. de los Hijos de Tomás Minuesa, 1930, pp. 23-25.

33 Carner-Ribalta, Josep: Macià. La seva actuació a lestranger, México, Edicions Catalanes de Méxic, 1952, vo. I, pp. 50-51; UCELAY DA CAL, Enric: Estat Català: The strategies of separation and revolution of catalan radical nationalism (1919-1933), Ph. D. Columbia University. Ann Arbor (Mi.)Londres, University Microfilms International, 1979, p. 154; VIBRANT (seud. de Daniel CARDONA CIVIT): Res de nou al Pirineu, Barcelona, Nosaltres Sols!, 1933, pp. 51-54 y XuRIGUERA, Ramón: Els exiliats acusen, Badalona, Edicions Proa, 1930, p. 164. 
separatista) fueron animados a adherirse al Touring Club de Francia para dar un tono más inocuo a las marchas que efectuaban en la Île-de-France, el Midi y la Saboya ${ }^{34}$. Hacia mayo de 1925 , Macià ya calculaba que, con sus seguidores domiciliados en París, Toulouse, Beziers, Perpignan, Ceret y Cette, podía reunir una fuerza de tres o cuatro centenares de combatientes para pasar los Pirineos, aunque el mayor control policial establecido tras la llegada al poder del gobierno conservador de Painlevé-Caillaux obligó a Estat Català a pasar definitivamente a la clandestinidad ese verano. Por si fuera poco, en noviembre Macià sufrió la defección del grupo disidente de Cardona, centrado en Beziers, y de parte de la militancia catalanista de Perpignan, en desacuerdo con la excesiva prudencia de sus planteamientos políticos.

También se habían establecido desde 1925 contactos con italianos antifascistas, recientemente exiliados tras el affaire Matteotti y la asunción de la dictadura por Mussolini. La relación entre ambas comunidades de emigrados, hermanadas sentimentalmente por la francofilia demostrada en las trincheras de la Gran Guerra, por una similar tradición republicana, por el nacionalismo irredentista y por la crítica a la admiración mutua que se profesaban ambos dictadores mediterráneos, se realizó casi de forma espontánea, y con el beneplácito de algunos grupos de apoyo de inequívoco talante democrático, como la Ligue Française des Droits de l'Homme, la Francmasonería, los librepensadores de las Sociétés Savantes, etc. La Legione Garibaldina della Libertà estaba dirigida por Riciotti Garibaldi, nieto del héroe del Risorgimento, que era en realidad un agente provocador a sueldo del gobierno de Roma. La "conexión italiana» hizo derivar una conjura trazada de forma más o menos convencional en una rocambolesca maniobra provocativa de «baja política» internacional. Garibaldi informó de los preparativos insurreccionales a Mussolini, quien filtró algunas informaciones a Primo de Rivera, peró no al gobierno galo, con el fin de enemistar al primero por la inacción del segundo y atraerle a una colaboración en el Mediterráneo en detrimento de Francia. Sin embargo, la Sûreté seguía una pista convergente que le permitió desactivar in extremis el complot en las cercanías de Prats de Molló el 2 de noviembre de 1926, cuando las diferentes expediciones armadas (Andorra-Seo de Urgell-Puigcerdà, Burdeos-Toulouse y Lyon-Perpignan) estaban a punto de pasar la frontera con dirección a Olot y Figueras ${ }^{35}$

34 Según Juan Antonio Fernández Huertas, policía secreto adscrito a ese Consulado, en la zona de la frontera hasta Port-Bou (Canet, Beziers, Perpignan) se habían formado grupos catalanistas que ensayaban tácticas de lucha armada con el apoyo económico recibido de América. En Toulouse, el Comité estaba formado por el dr. José Cabré Claramunt, Ramón Vila y Fos y otro personaje no identificado. Entre los documentos interceptados aparecía una carta de Macià a F. Vilalta de Toulouse (15-IX-1924) donde preguntaba si disponían de fondos para colaborar con el grupo de Perpignan en marchas conjuntas de entrenamiento cerca de la frontera (AGA, Asuntos Exteriores, Embajada en París, caja $n^{\circ}$ 6331).

35 El 1-XI, la Policía francesa detuvo en la estación de Estagel, cerca de Perpignan, a 13 españoles y 9 italianos procedentes de París y Toulouse. Al día siguiente fueron detenidos en Millas seis

Hispania, LXII/2, núm. 211 (2002) 483-504 
Después de haber sido absuelto en el juicio por la intentona de Prats de Molló, Macià marchó a Bruselas en marzo de 1927, donde siguió urdiendo nuevos y fantásticos planes revolucionarios hasta que a fines de año decidió dar el salto a América. Los dirigentes nacionalistas exiliados no volverían a Cataluña hasta febrero de 1931, a punto para constituir la gran coalición de izquierda republicana que resultaría triunfadora en Cataluña en las elecciones municipales del mes de abril.

\section{LOS TORTUOSOS MEANDROS DE LA DEFENSA EXTERIOR DEL RÉGIMEN DICTATORIAL}

El amplio espectro de actitudes opositoras que tuvo que afrontar Primo de Rivera, y su desembocadura en una cadena de conjuras e insurrecciones fallidas, hizo del control de la emigración política un asunto prioritario de gobierno, que derivó en ocasiones en una auténtica cuestión de Estado. El carácter dictatorial del régimen hacía imposible alguna de las estrategias de defensa que se habían ensayado en el pasado, como la concertación policial y jurídica a escala internacional. Peor aún, la concentración del exilio en un país que, como Francia, mantuvo durante los años clave de la década de los veinte un gobierno y una opinión pública nada proclives a veleidades autoritarias, transformó la vigilancia y la represión de exilio en una cuestión de alto voltaje, donde no faltaron argucias de baja diplomacia y maniobras provocativas.

La peculiar figura del embajador español José María Quiñones de León resulta esencial para entender las intrincadas relaciones entre diplomacia y acción policial. Alternando las labores de Fouché con las de Talleyrand, Quiñones denunciaba ante el Quai d'Orsay las maniobras conspirativas de los diversos focos de exiliados para forzar un recorte de sus derechos como refugiados políticos y propiciar su expulsión, como sucedió con Macià en 1927 o con el general López de Ochoa en 1929. Como a inicios de la Restauración, el embajador en París se transformó en la pieza clave de la intrincada red de vigilancia tejida en torno a los emigrados. Quiñones envió instrucciones a los cónsules del Midi para que intensificasen su tradicional colaboración con las autoridades fronteri-

\footnotetext{
españoles y 11 italianos, todos con edades que rondaban los 20-30 años (AGA, Asuntos Exteriores, Embajada en París, caja $n^{\circ}$ 6100). Se practicaron nuevas detenciones en Prats el 4-XI (19 catalanes), en Prades el 2-XI (un catalán), en Perpignan el 2 y 3-XI (entre 28 y 47 españoles y 9 italianos, liderados por Jaume Miravitlles), en St. Laurent de Cerdans el 4-XI (15 catalanes), además de 30 españoles y 12 italianos en Burdeos y los Pirineos. Vid. telegrama personal y reservado (2-XI-1926, 14 h.) y despacho de la Embajada España (2-XI-1926) al Ministerio de Estado, y la «Liste des Espagnols arrêtés» (27-XI-1926) remitida por la Préfecture des Pyrenées Orientales (AGA, Asuntos Exteriores, Embajada en París, caja caja ${ }^{\circ}$ 6101). La lista de detenidos, en Estat CATALÀ, La Catalogne rebelle, París, Agence Mondiale de Librairie, 1927, pp. 34-35 y telegrama del Ministerio de Estado al ministro de la Gobernación y al presidente del Consejo (5-XI-1926), en AMAE, leg. R. 28, exp. 29.
}

Hispania, LXII/2, núm. 211 (2002) 483-504 
zas y potenció las actividades de los policías adscritos al servicio exterior. Desde los primeros pasos de la Dictadura, los funcionarios vinculados tradicionalmente a los consulados del Sur de Francia fueron reforzados con otros agentes dependientes directámente de la Dirección General de Seguridad, lo que enconó los conflictos de competencia hasta que, tras una prolongada etapa de estrechez económica, la crisis presupuestaria de 1929 obligó a un drástico reajuste de plantillas ${ }^{36}$.

Los policías enviados por la Dirección General de Seguridad eran sólo una de las bazas con que contaba la Embajada para el control del exilio. Quiñones potenció un abigarrado equipo de espías, confidentes y agentes provocadores perfectamente relacionados con la Policía parisina merced a la buena amistad que mantenía con el polémico prefecto Jean Chiappe, el ministro del ramo André Tardieu, el sempiterno ministro de Exteriores Aristide Briand y buena parte de los prefectos departamentales y las autoridades fronterizas ${ }^{37}$. Sin embargo, las continuas presiones ejercidas por Quiñones sobre el gobierno francés para poner coto a los manejos revolucionarios de catalanistas y anarquistas no arrojaron los resultados esperados. El primer ministro Edouard Herriot, que no compartía en absoluto la filosofía del diplomático español sobre el recorte de los derechos individuales de los refugiados, transigió en ordenar el alejamiento de la frontera de Macià, pero prefirió expulsar a una veintena de anarquistas hacia Bélgica antes que librarlos al rigor del Directorio ${ }^{38}$. La ineficacia de este

36 Informe del Consulado en Toulouse (29-II-1924) sobre el envío de un policía adscrito a la Embajada y otro de la DGS que actuaba por su cuenta (AGA, Asuntos Exteriores, Embajada en París, caja $n^{\circ}$ 6331). El 14-XI-1924, el cónsul en Bayona se quejaba de la falta de subvenciones para servicio de vigilancia (AGA, Asuntos Exteriores, Embajada en París, caja ${ }^{\circ}$ 6330). La supresión de los servicios de Policía en los consulados de Toulouse (Luis Quintana) y Marsella (Manuel Ariño) por resolución de 26-IV-1929, en AGA, Asuntos Exteriores, Embajada en París, caja n ${ }^{\circ} 6194$.

37 Vid. «Visite de l'ambassadeur d'Espagne à M. de Peretti» (10-I-1924), donde Quiñones se felicita de sus excelentes relaciones con las autoridades de las localidades fronterizas. Como muestra de esta sintonía, la Prefectura de Policía de París invitó a los organizadores de una reunión catalanista que debía celebrarse el 16-III-1924 en el Casal Català (grupo separatista catalán de París, que se fusionó con la Asociación Radical Catalana) a que se abstuviesen en lo sucesivo de manifestaciones de esa naturaleza en el territorio francés (Ministère de IIntérieur a Quai d'Orsay, 15-III-1924). Toda esta documentación, en AQO, Série Z, Europe, 1918-1929, Espagne, leg. 45, pp. 1, 11-13 y 31, respectivamente. El pago de la vigilancia sobre los exiliados, aceptada por Chiappe y Tardieu, en PrECioso, Artemio: Españoles en el destierro, Madrid, Ed. Vulcano, 1930, pp. 155-164. Sobre las frecuentes entrevistas de Chiappe con Martínez Anido y con el director general de Seguridad Pedro Bazán en París para coordinar las labores de vigilancia, y los viajes a Madrid del jefe de la Sûreté en Hendaya, M. Picard, vid. «España y Francia», El Murciélago, n 4, ca. XII-1929, p. 1-2.

38 Nota del presidente del Consejo y ministro de Asuntos Exteriores al embajador español, 29XI-1924. Herriot reprochó a León y Castillo su confusión de los derechos políticos con los derechos públicos que el Estado francés garantizaba sin discriminación. La solicitud de extradición de los 17 detenidos en Bayona por la irrupción de Vera, en informe de Quiñones al presidente del Directorio (16-IV-1925). Según mensaje del cónsul en esta localidad (27-XI-1924) de los veinte españoles detenidos por la Gendarmerie, 17 indocumentados fueron expulsados a Bélgica antes de que el go- 
tipo de negociaciones diplomáticas persuadió a ciertos responsables de la Policía española de que era necesario ejercer presiones más enérgicas sobre el gabinete francés para obtener una resolución favorable en el pleito de los emigrados. En este contexto de frialdad en la relaciones entre ambos gobiernos se explica la gaffe policial de Vera de Bidasoa del otoño de 1925, cuando un grupo de agentes de la Brigada de Investigación Social de la DGS simuló un enfrentamiento armado en la frontera navarra que brindase la coartada para presionar al gobierno francés y exigirle el alejamiento de la frontera de Miguel de Unamuno, Eduardo Ortega y Gasset y otros exiliados catalanistas y libertarios ${ }^{39}$.

A medida que el Cartel des Gauches entraba en crisis, la vigilancia sobre los emigrados se hizo más estricta, e incluso la prensa de oposición al régimen español fue sometida a creciente fiscalización. La presión acabó por hacerse asfixiante con la crisis del Cartel y la desarticulación del complot llamado de la «Sanjuanada» en la primavera-verano de 1926. Este incidente y otros similares abrieron un período de mayor beligerancia del gobierno francés contra los emigrados políticos: entre 1921 y 1927 fueron expulsados por actividad política 92 españoles, y en varios procesos se dictaron tres condenas leves y 217 expulsiones ${ }^{40}$.

\section{OTROS TIPOS DE EXILIO, OTRAS FORMAS DE OPOSICIÓN: LAS PERSONALI- DADES INTELECTUALES Y POLÍTICAS EMIGRADAS Y LA LUCHA CONTRA LA DIC- TADURA Y LA MONARQUÍA}

A pesar de su espectacularidad, el eco propagandístico de las actividades armadas de anarquistas y separatistas quedó limitado en España por la estricta censura de prensa. Mayor resonancia alcanzaron las manifestaciones de destacadas individualidades de la cultura y la política que sufrieron un exilio voluntario o forzoso. Quizás la figura que obtuvo más notoriedad pública en su labor de oposición a la Dictadura fue Miguel de Unamuno. Confinado en Fuerteventura junto a Rodrigo Soriano tras la clausura del Ateneo en febrero de 1924, fue espectacularmente liberado el 9 de julio de 1924 gracias al auxilio prestado por el director del diario parisino Le Quotidien. Esta peripecia, llevada a cabo más por razones publicitarias que por un reflejo consciente de rebeldía política, le transformó en uno de los exiliados españoles más populares de Francia, un

\footnotetext{
bierno español hubiera tenido tiempo de cursar la solicitud de extradición. En cuanto a los detenidos en Perpignan, sólo fueron condenados a 15 días de prisión y 50 francos de multa por tenencia de armas prohibidas (telegrama de Quiñones al ministro de Estado, 18-XI-1924, 20:00 h., en AGA, Asuntos Exteriores, Embajada en París, caja $n^{\circ}$ 6330).

39 Sobre esta cuestión, vid. GONZÁlEZ CALLEJA, Eduardo: El máuser y el sufragio. Orden público, subversión y violencia política en la crisis de la Restauración (1917-1931), Madrid, CSIC, 1999. pp. 288-290.

40 Compárese esta cifra con las 42 extradiciones de etarras dictadas por el gobierno francés entre 1984 y 1996, y reseñadas por MORÁN, Sagrario: ETA, entre España y Francia, Madrid, Ed. Complutense, 1997 , pp. $453-458$.
}

Hispania, LXII/2, núm. 211 (2002) 483-504 
poco por encima del venerable Macià y casi a la altura del semidiós Blasco Ibá$\tilde{n} e z^{41}$. Haciendo tándem con Eduardo Ortega y Gasset, Unamuno inició una campaña de acoso publicitario a la Dictadura, lanzado a fines de 1924 la revista España con Honra, y alquilando por esas mismas fechas unos aeroplanos que sobrevolaban San Sebastián con grandes letreros en favor de la «Libertad» y de la «República Española» pintados en sus carlingas ${ }^{42}$. Al tiempo, ambos desterrados mantenían contactos con el Comité de Relaciones Anarquistas para apoyar con dinero y actos de propaganda una incursión armada por la frontera pirenaica que derivó en los hechos de Vera de Bidasoa.

En abril de 1927, Unamuno y Ortega y Gasset iniciaron entre Hendaya, Burdeos, Bayona y París la publicación de la revista clandestina Hojas Libres, que gracias a la mayor fiabilidad de sus noticias, al prestigio de algunos de sus colaboradores (Rodrigo Soriano, Carlos Esplá, Joan Casanovas, etc.), al diminuto formato que facilitaba su pase clandestino a España y a la posibilidad de obtener suscripciones discretas, se transformaron en una referencia informativa obligada de la oposición a la Dictadura. El éxito incontestable que tuvieron las Hojas Libres en ciertas capas, necesariamente restringidas, de la población española no oculta la plétora de revistas clandestinas de menor tirada publicadas en el extranjero - sobre todo en Francia - al hilo de los sucesivos exilios, conspiraciones o declaraciones de disidencia política: España con Honra, dirigida por Carlos Esplá, estaba apoyada financieramente por Santiago Alba y sobre todo por Blasco Ibáñez. El Murciélago era confeccionado en San Juan de Luz por el entorno conspirativo de Miguel Villanueva y Luis Rodríguez de Viguri. En el campo anarquista, a Iberion le sucedió en 1924 Tiempos Nuevos, que tiraba 12.000 ejemplares en octubre de 1925 , y en el que colaboró Rodrigo Soriano con unas celebradas Memorias apócrifas de Alfonso XIII. Las diferentes tendencias del separatismo catalán patrocinaban su propia prensa (Le Courrier $\mathrm{Ca}$ talan, Catalunya Lliure, Butlletí d'Estat Català, La Bandera Negra, Rebel.lió Catalana, etc.), que era apoyada por los boletines de la emigración en América y por ciertos diarios y revistas culturales del Rosellón y la Cerdaña.

La actitud de la vieja clase política de la Restauración estuvo marcada, al menos hasta 1926, por la impotencia y la desorientación. En la práctica, sólo un puñado de políticos dinásticos decidió seguir los pasos de Prim o de Ruiz Zorrilla, organizando desde el exterior una resistencia eficaz sobre la base teóri-

41 Sobre el confinamiento y huida de Unamuno de Fuerteventura, vid. ARCo LÓPEZ, Valentín del: «Unamuno frente a Primo de Rivera», en Studia Historica. Contemporánea, vol. VI, $\mathrm{n}^{\circ} 4,1986$, pp. 166-168 e Intelectuales frente a la Dictadura de Primo de Rivera. Unamuno y el Grupo de París, Salamanca, Ediciones Universidad de Salamanca, 1987 y GARCíA QUEIPO DE LLANO, Genoveva: Los intelectuales y la dictadura de Primo de Rivera, Madrid, Alianza, 1988, pp. 55-59 y 121-147. El testimonio del propio Unamuno, Miguel de: De Fuerteventura a París: Diario intimo de confinamiento y destierro vertido en sonetos, $9^{\mathrm{a}}$ ed., París, Excelsior, 1925.

42 ARCo López, «Unamuno frente a Primo de Rivera», pp. 178-179 y AGA, Asuntos Exteriores, Embajada en París, caja $n^{\circ} 6330$. 
ca de la defensa de los principios del liberalismo clásico. Dejando a un lado el temprano refugio de Santiago Alba en París, la figura más sobresaliente de este peculiar sector del exilio fue el ex-primer ministro conservador José Sánchez Guerra, que inició un destierro voluntario en septiembre de 1927, como protesta por los ensayos de consolidación institucional de la Dictadura. Refugiado en París, dos meses después inició contactos con políticos de muy diversas tendencias (el marqués de Lema, Santiago Alba, Miguel Villanueva, Manuel Burgos y Mazo, Vicente Blasco Ibáñez o Indalecio Prieto) para impulsar una conspiración que permitiera el establecimiento de una república de tonos moderados, para lo cual se contaba con el apoyo de las logias masónicas, de dirigentes republicanos como Lerroux o Marcelino Domingo y de personalidades del radicalismo francés como Edouard Herriot ${ }^{43}$. El plan, que al parecer fue puesto a punto por Alba, Marañón, Unamuno, Sánchez Guerra y otras personalidades de la disidencia liberal y conservadora en varias reuniones celebradas en Biarritz, fue llevado en práctica por Sánchez Guerra el 29 de enero de 1929, tras una accidentada singladura desde la costa meridional de Francia hasta las playas de Valencia donde intentó en vano levantar al $5^{\circ}$ Regiminto de Artillería Ligera.

La mayor parte de los exiliados pudo retornar a España a inicios de 1930, merced a las medidas de gracia dictadas por el Gobierno Berenguer. La insurrección de fines de ese año provocó la última y efímera oleada de refugiados políticos, en su mayor parte militares que habían logrado escapar por vía aérea desde Cuatro Vientos hasta Portugal, donde fueron autorizados a escoger sus puntos de destino definitivo ${ }^{44}$. El 15 de abril de 1931, en algún lugar del trayecto entre Madrid y la frontera francesa, el último grupo de desterrados republicanos (Queipo de Llano, Franco, Rada, Ignacio Hidalgo de Cisneros, Prieto, Domingo, D'Olwer, Martínez Barrio...) se cruzó con el convoy que conducía a la familia real camino del exilio. Poco después, un puñado de monárquicos irreductibles decidió instalarse de forma permanente en sus lugares de veraneo en la costa francesa (San Juan de Luz, Biarritz), inaugurando la particular Coblenza de donde partirían las primeras amenazas violentas contra el régimen recién instaurado ${ }^{45}$.

\footnotetext{
43 Informe reservado del cónsul general, Romanelli, al embajador de Italia en Madrid (29-XII1927), en ASMAE, Affari Politici, 1919-1930, Spagna, 1927-1928, caja 1591.

44 Ramón Franco y Pablo Rada eligieron Francia, Alemania, Argentina y Urguay; Queipo escogió Francia, Bélgica y Holanda, el mayor Ángel Pastor, José Puig, Carlos Roa, José La Roquette, Antonio Rexach y José Martínez Aragón optaron por Francia, Bélgica, Holanda y Alemania.

45 Sobre esta cuestión, vid. GonZÁlEZ, Nazario: «Los exiliados monárquicos durante la Segunda República», en Ponencias del II Coloquio Internacional sobre la Segunda República. Barcelona, Publicacions Edicions Universitat de Barcelona, 1983, pp. 37-47.
} 


\section{CONCLUSIONES: UNA REIVINDICACIÓN DE LA EMIGRACIÓN POLÍTICA CO- MO FACTOR DE POLÍTICA INTERIOR Y EXTERIOR}

El estudio de la emigración política permite revisar una serie de tópicos muy al uso en la actual historiografía legitimadora del régimen canovista: en primer lugar, el aserto de que la Restauración fue un modelo de estabilidad política. Por el contrario, la amenazadora presencia de los exiliados fue una realidad recurrente que, como dijo Cánovas al referirse las actividades carlistas y republicanas de los años setenta y ochenta, tuvo en algunos momentos al régimen "pendiente de un hilo». Aunque, a la larga, la violencia desplegada desde el exterior no afectase sino de forma puntual y poco decisiva a la dinámica política de la Restauración, la repudiable imagen internacional de un régimen permanentemente a la defensiva, «recogido» en sus propios problemas, debe tanto a la incapacidad o temor a desarrollar una acción diplomática más ágil y dinámica como a la psicosis de peligro que suscitaban los emigrados políticos establecidos en el extranjero.

Vista la dureza de la acción represiva dirigida contra la disidencia más irreductible del interior y el exterior, la Restauración no aparece como el sistema político conciliador, transigente y abierto que ahora se pinta desde algunos pagos historiográficos. Por el contrario, el régimen no tuvo contemplaciones con aquellos grupos políticos que se situaban en oposición frontal al sistema, y marcaba el camino del paredón, la cárcel o el exilio a los disidentes que optaban por una resistencia más activa, fuera ésta o no de tipo armado. Bien es cierto que las estrategias defensivas del Estado sufrieron grandes cambios, sobre todo cuando la Dictadura primorriverista tuvo que potenciar los propios recursos coercitivos ante la falta de apoyo internacional. Fue en ese contexto de excepcionalidad política cuando se produjeron las mayores tensiones diplomáticas y las irregularidades más flagrantes en la vigilancia de los exiliados.

El tercer tópico a rechazar es el que da por cierta la simpatía de los gobiernos de los países vecinos, y más en concreto de Francia, a las actividades políticas de las diversas oleadas de emigrados. En la práctica, y a la luz de la documentación policial y diplomática disponible, cabe asegurar que los gobiernos de la Tercera República, al igual que el resto de los gabinetes europeos de la época, mantuvieron una colaboración leal e incluso estrecha con España en la lucha antisubversiva, pero con tres grandes condicionamientos: la garantía del derecho de asilo para los refugiados políticos, la obsesión manifestada por los gabinetes republicanos de no provocar las iras del sector más avanzado de su opinión pública, y los conflictos, no por episódicos menos dramáticos, entre gobiernos y regímenes de distinto signo. Tal fue el caso de las tensiones fronterizas durante los balbuceos de la República Portuguesa, la actitud del Bloc des Gauches liderado por los radicales franceses desde 1902 hasta la Gran Guerra respecto la política de los gobiernos conservadores españoles (sobre todo en torno a la crisis de 1909), y el escaso aprecio mostrado desde el Cartel des Gauches (1924-1926) por la Dictadura de Primo de Rivera. 
Las formas resistenciales ensayadas por las diversas oleadas de emigrados políticos nos muestran el valor simbólico de las tradiciones de oposición heredadas del exilio liberal decimonónico, y la creciente importancia que fueron cobrando las redes de vinculación transnacional, tanto en el potenciamiento de la estructura de oportunidades de los grupos disidentes como en el reforzamiento de lă capacidad represiva de los Estados. Sea como fuere, el estudio de este peculiar modo de acción colectiva nos permite sacar a la luz aspectos inéditos de la gestión interior de un sistema político, y nos puede ayudar a ofrecer explicaciones más complejas y satisfactorias de algunas decisiones de su política exterior. 